\title{
INDICADORES DE DIVERSIDADE PARA A ARBORIZAÇÃO VIÁRIA DO BAIRRO CENTRO NORTE DA CIDADE DE DOIS VIZINHOS - PARANÁ
}

\author{
INDICATORS OF DIVERSITY FOR ROAD AFFORESTATION OF CENTER NORTH \\ NEIGHBORHOOD OF DOIS VIZINHOS CITY - PARANÁ
}

\author{
Suzamara Biz¹; Aline Paula Pastório2; Flávia Gizele König Brun³; Eleandro José Brun; \\ Luciano Farinha Watzlawich ${ }^{5}$
}

\begin{abstract}
RESUMO
O trabalho teve por objetivo realizar um diagnóstico da cobertura arbóreo para conhecer a distribuição e a diversidade, avaliar o Índice de Cobertura Arbórea (ICA) e o índice de Cobertura Vegetal (ICV) para definição da quantidade de espécies e indivíduos visando a adequação da arborização viária do Bairro Centro Norte da Cidade de Dois Vizinhos - PR. O levantamento da arborização urbana foi do tipo censo quali-quantitativo. Os dados foram tabulados no Microsoft Office Excel ${ }^{\circledR}$, sendo realizadas análises dos dados qualitativos e quantitativos, calculados os Índices de Cobertura Arbórea, Índice de Cobertura Vegetal e Índice de Diversidade de Odum. O censo apontou a presença de 1.206 árvores de 63 espécies e 28 famílias, número que demonstra um déficit de arborização, pois o bairro comportaria 1.371 árvores distribuídas adequadamente ao longo das vias. O Bairro Centro Norte apresentou Índice de Cobertura Vegetal de 17,3 m2/habitante, e Índice de Cobertura Arbórea de 28\%. O Índice de Diversidade de Odum para todo o bairro atingiu valor de 2,01, sendo considerado abaixo do adequado. Após os cálculos para a indicação de uma arborização adequada, chegou-se ao valor de 3,34 como sendo ideal para o bairro.
\end{abstract}

Palavras-chave: Árvores urbanas; Qualidade ambiental; Cobertura vegetal; Planejamento.

\section{ABSTRACT}

The study aimed to carry out a diagnosis of tree coverage to know the distribution and diversity, evaluate the Arboreal Coverage Ratio (ICA) and the Vegetation Cover Index (ICV) to define the number of species and individuals in order to adequate the afforestation road of Center North Neighborhood of Dois Vizinhos City - PR. The survey of urban trees was the qualitative and quantitative census type. Data were tabulated in Microsoft Office Excel® , being carried out analyzes of qualitative and quantitative data, calculated the Arboreal Coverage Ratios, Coverage Ratio and Odum Plant Diversity Index. The census pointed out the presence of 1,206 trees of 63 species and 28 families, a number that demonstrates an afforestation deficit as the neighborhood behave properly distributed 1,371 trees along the roads. The North Central District presented Vegetation Cover Index of $17.3 \mathrm{~m} 2 /$ inhabitant, and Arboreal Coverage Ratio of $28 \%$. The Odum Diversity Index for the whole district reached the value of 2.01 and is considered below appropriate. After the calculations for the indication of an appropriate afforestation, came to the 3.34 value as ideal for the neighborhood.

Keywords: Urban trees; Environment quality; Vegetation coverage; Planning.

\footnotetext{
Recebido em 23.10.2015 e aceito em 15.12.2015

1 Engenheira Florestal, Mestranda em Agronomia, Universidade Estadual do Centro-Oeste, Guarapuava, PR. E-mail: suzamarabiz@gmail.com

2 Engenheira Florestal pela Universidade Tecnológica Federal do Paraná, Campus Dois Vizinhos, Dois Vizinhos, PR, Brasil. Email: aline_paula8@hotmail.com

3 Engenheira Florestal, Dra., Professora e coordenadora do grupo de Silvicultura Urbana da Universidade Tecnológica Federal do Paraná- Campus Dois Vizinhos, PR. E-mail: flaviagbrun@gmail.com

4 Engenheira Florestal, Dr., Professor e coordenadora do grupo PET Engenharia Florestal da Universidade Tecnológica Federal do Paraná- Campus Dois Vizinhos, PR. E-mail: eleandrobrun.utfpr@gmail.com

5 Professor Dr. da Universidade Estadual do Centro Oeste do Paraná, Guarapuava, PR, Brasil. E-mail: farinha@unicentro.br
} 


\section{INTRODUÇÃO}

Atualmente a vegetação urbana é considerada um elemento de vital importância não só para a composição da paisagem, como também, desempenhando papel primordial na melhoria das condições ambientais (SANTOS et al., 2013).

A arborização no meio urbano desempenha importante função para a população e para o ambiente, ajuda a controlar a poluição atmosférica e sonora, ameniza o clima reduzindo ou mesmo evitando ilhas de calor, contribui na redução da amplitude térmica, diminuição do aquecimento local e dos custos de refrigeração, auxilia na conservação da água, redução da erosão, além de promover a biodiversidade, e contribuir com à saúde psicológica e social dos habitantes e o embelezamento das cidades (MASCARÓ; MASCARÓ, 2005; ROPPA et al., 2007; NOWAK et al., 2008).

Contudo, para que a vegetação urbana desempenhe sua função, é preciso que as árvores plantadas disponham de espaçamento adequado para se desenvolverem, bem como, o plantio contemple determinada diversidade de espécies. Para conseguir isto, um planejamento pré-plantio deve ser feito, ou então, um replanejamento após o trabalho de arborização, sendo, no segundo caso, necessário o conhecimento do patrimônio arbóreo existente, o que pode ser feito por meio do inventário de árvores e às espécies que pertencem (SANTOS et al., 2013).

Portanto, para alcançar a qualidade do ambiente urbano, é necessário realizar um planejamento prévio para a implantação da arborização. Entretanto, poucas cidades brasileiras possuem um planejamento para as suas vias públicas (ANDREATTA et al., 2011). Então, quando a arborização não ocorre de forma planejada, inúmeros problemas podem ocorrer e, em vez de um elemento benéfico, a arborização passa a representar um foco de conflito nas cidades (COLETTO et al., 2008).

Quando ocorrem estas situações da ausência de um planejamento inicial é necessário que ações de replanejamento e manejo sejam realizados, para garantir a qualidade da vegetação urbana e consequentemente o desempenho das funções dessa vegetação.

O passo inicial para o desenvolvimento de um bom plano de manejo é a realização de um inventário, pois, o diagnóstico da arborização servirá de base para o planejamento da arborização, assim como para definição das práticas de manejo e monitoramento mais adequadas.

O inventário irá fornecer informações quali-quantitativas de espécies encontradas na arborização viária e suas condições. Além disso, o inventário permite obter informações dos chamados índices de riqueza ou variedade, que são indicadores de diversidade úteis na 
análise, podendo ser usados nas decisões de manejo e Planos Diretores de arborização (SILVA FILHO; BORTOLETO, 2005; ANGELIS NETO et al., 2006).

Um dos indicadores mais utilizados é o Índice de Áreas Verdes (IAV), que apresenta a quantidade de espaços livres / áreas verdes de uso público, em $\mathrm{km}^{2}$ ou $\mathrm{m}^{2}$ dividido pela quantidade de habitantes de uma cidade (TOLEDO; SANTOS, 2008).

Outro índice que pode ser utilizado é o Índice de Cobertura Vegetal em área urbana. Para obtenção desse índice é necessário o mapeamento de toda cobertura vegetal de um bairro ou cidade e posteriormente quantificá-la em $\mathrm{m}^{2}$ ou $\mathrm{km}^{2}$. Conhecendo-se a área total estudada, também em $\mathrm{m}^{2}$ ou $\mathrm{km}^{2}$, chega-se posteriormente à porcentagem de cobertura vegetal que existe naquele bairro ou cidade (ARRUDA et al., 2013). Para Melazo e Nishiyama (2010) o mapeamento da cobertura vegetal associado aos índices calculados além de importantes, também sevem para alertar o poder público e sociedade civil, sobre a real situação da arborização.

Desta forma, o presente trabalho teve por objetivo realizar um diagnóstico da cobertura arbórea do Bairro Centro Norte da cidade de Dois Vizinhos - PR, a fim de conhecer a distribuição e a diversidade de espécies vegetais presentes, assim como, avaliar o Índice de Cobertura Arbórea (ICA) e o índice de Cobertura Vegetal (ICV), para a definição da quantidade de espécies e de indivíduos necessários para a adequação da arborização viária local.

\section{MATERIAL E MÉTODOS}

\section{Área de estudo}

O estudo foi desenvolvido na cidade de Dois Vizinhos, Sudoeste do Paraná, nas

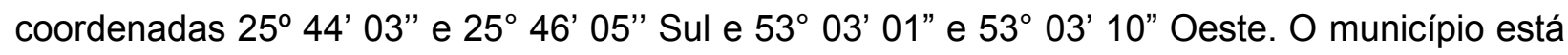
situado no Terceiro Planalto Paranaense, apresentando altitude média de 509 metros (IBGE, 2010).

O clima, segundo a classificação de Köppen é do tipo Cfa, subtropical úmido mesotérmico (ALVARES et al., 2013). A cidade encontra-se no ecótono entre a Floresta Estacional Semi-decidual, juntamente com a Floresta Ombrófila Mista (IBGE, 2010). O município apresenta 418,65 km² de área e uma população de 36.179 habitantes, sendo que a população residente na área urbana é igual a 28.095 pessoas (IBGE, 2010).

A área inventariada se localizada no Bairro Centro Norte de Dois Vizinhos, o bairro com maior concentração das atividades econômicas e que apresenta visualmente, maior arborização em comparação aos demais bairros da cidade. A área em estudo é limitada entre a 
Rua Dom Pedro e a Avenida Prefeito Dedi Barrichelo Montagner e pelas Ruas Castro Alves e Avenida Presidente Castelo Branco, conforme o mapa da Figura 1.

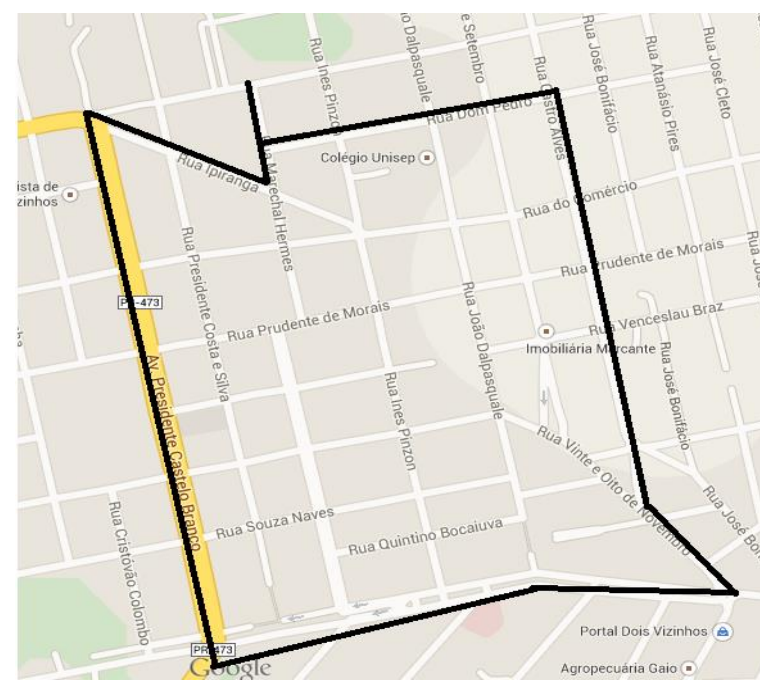

Figura 1. Localização da área de estudo na cidade de Dois Vizinhos - Paraná

Figure 1. Study area localization in the Dois Vizinhos city - Paraná

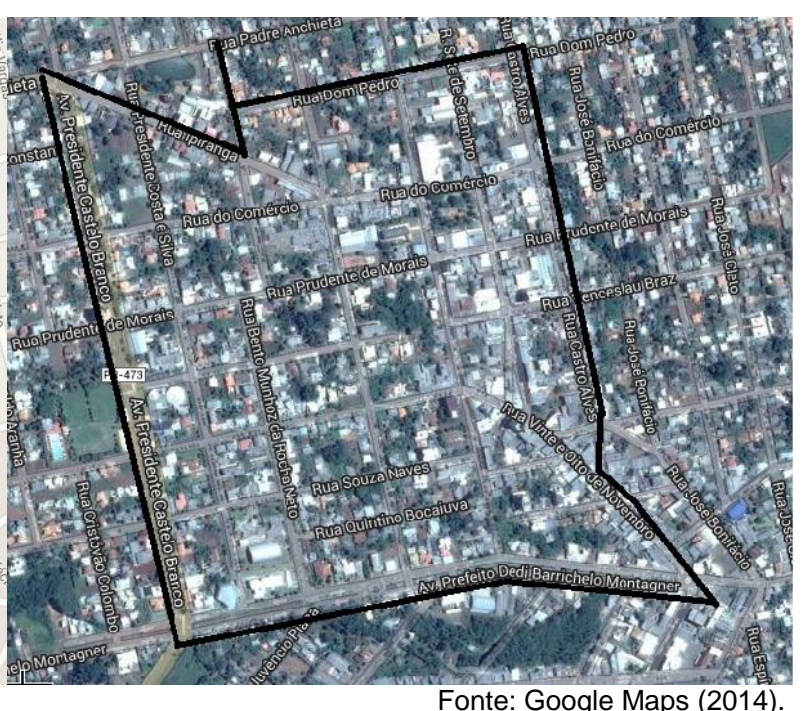

Fonte: Google Maps (2014).

\section{Metodologia}

A arborização da cidade foi analisada por meio de censo, ou seja, todas as árvores foram contadas e analisadas individualmente de forma quali-quantitativa. Para tanto, além da identificação botânica, da altura total e da altura de copa, também foi calculada para todas as árvores a área de copa $\left(\mathrm{em} \mathrm{m}^{2}\right)$. A área de copa (AC) foi calculada com base na medida de quatro raios equidistantes $90^{\circ}$ entre si, com o emprego de trena métrica de $30 \mathrm{~m}$. Também foram consideradas as seguintes variáveis: largura da rua e calçada $(m)$, comprimento da calçada e da rua $(\mathrm{m})$, que foi aferida com auxílio de trena métrica de $30 \mathrm{~m}$. Com a análise destas condições foi possível conhecer a real situação de cada indivíduo arbóreo dentro do bairro e desta forma, propor ações de manejo, caso seja necessário.

Concluída a coleta de dados, estes foram compilados e digitados em planilha eletrônica do programa Microsoft Office Excel, e posteriormente, utilizados para o cálculo dos índices de arborização apresentados a seguir.

a) Índice de cobertura arbórea (ICA)

Conforme Arruda et al. (2013), o Índice de Cobertura Arbórea tem a função de fornecer o percentual de cobertura da arborização nas ruas, dado pela equação: 


$$
\mathrm{ICA}=\left[\frac{\sum_{\mathrm{i}=1}^{\mathrm{n}} \mathrm{AC}}{\sum_{\mathrm{i}=1}^{\mathrm{n}} \mathrm{AR}}\right] \times 100
$$

Onde:

ICA = Índice de Cobertura Arbórea (\%);

$\mathrm{n}=$ número de ruas inventariadas;

$\mathrm{AC}=$ Área de Copa das Árvores $\left(\mathrm{m}^{2}\right)$;

$\mathrm{AR}=$ Área da Rua $\left(\mathrm{m}^{2}\right)$;

b) Índice de cobertura vegetal (ICV)

O índice de cobertura vegetal fornece a área de cobertura vegetal por habitante da cidade: conforme equação a seguir (HARDER et al,. 2006).

$$
\mathrm{ICV}=\frac{\sum \text { das áreas de copa }}{\mathrm{n} \text {. de habitantes da área urbana }}
$$

Onde:

IVC = Índice de Cobertura Vegetal ( $\mathrm{m}^{2} / \mathrm{hab}$.);

$\Sigma=$ Somatório das áreas de copa;

Número de habitantes do bairro.

c) Índice de diversidade de Odum $\left(\mathrm{d}_{1}\right)$

O Índice de Diversidade de Odum $\left(d_{1}\right)$ é uma importante ferramenta para o planejamento e adequação da arborização de vias públicas, pois, ele balizará a necessidade da diversificação de espécies na via ou até mesmo em caso extremos, a supressão de espécies inadequadas para a melhoria da prática de manejo no local (ODUM, 2001).

Este índice deve ser de 2,45, no mínimo, para ser considerado satisfatório e chegando a atingir no máximo 26,99. Entretanto não é desejável que o valor máximo seja atingido, pela baixa plasticidade estética proporcionada pela heterogeneidade, assim como dificuldades de manejo da arborização (SILVA FILHO; BORTOLETO, 2005). Obtido pela seguinte formula:

$$
d 1=\frac{(S-1)}{\ln N}
$$

Onde:

$\mathrm{d}_{1}=$ índice de diversidade;

$\mathrm{S}=$ número total de espécies;

$\mathrm{N}$ = Somatório do número de indivíduos. 
d) Índice de diversidade futura de Odum ( $\left.\mathrm{d}_{\mathrm{fut}}\right)$

Este índice refere-se ao valor máximo de espécies a serem implantadas (adicionadas) em uma via pública, para que seja alcançada a diversidade ideal de espécies, considerando que não se exceda a $10,0 \%$ de uma espécie numa paisagem urbana. Este cálculo é feito através da seguinte formula (SILVA FILHO; BORTOLETO, 2005):

$$
S_{a d i}=\left[d_{m i n}-d_{1}^{*} \ln \left(N_{e x i s t}-N_{p o t}\right)\right]+f c
$$

Onde:

$\mathrm{S}_{\mathrm{ad}}=$ Quantidade de espécies a serem adicionadas;

$\mathrm{d}_{\text {mín }}$ Índice de Odum teórico mínimo $(2,45)$;

d1 = Índice de Odum atual (calculado no inventário);

$\mathrm{N}_{\text {exist. }}=$ Somatória do número de espécies existentes (obtidas no inventário);

$\mathrm{N}_{\text {pot. }}=$ Somatória do número de indivíduos potenciais;

fc = Fator de correção $(5,5)$, utilizado para evitar que o índice resultante $(\mathrm{S}$ ad) do novo plantio não seja inferior ao dmín $(2,45)$.

Para o cálculo do número de árvores potenciais em uma via pública considera-se um espaçamento de 15,0 m entre as árvores, e que em 1,0 km nos dois lados da via se obtenha uma proporção de 133 árvores (SILVA FILHO; BORTOLETO, 2005):

$$
\mathrm{N}_{\text {pot }}=133-\mathrm{N}_{\text {exis }}
$$

Onde:

$\mathrm{N}_{\text {pot }}=$ Número de árvores potencial para a via;

133 = Número de árvores potenciais em 1 km, com espaçamento de 15 m entre árvores;

$\mathrm{N}_{\text {exist }}=$ Número de árvores existente na rua.

e) Índice de diversidade de Odum futuro $\left(\mathrm{d}_{2}\right)$

Para o cálculo de diversidade futura da via pública após a adição de novas espécies (Sad) utiliza-se o Índice de Odum Futuro $\left(d_{2}\right)$ : através da seguinte expressão (ODUM, 2001).

$$
d_{2}=\frac{\left(S_{a d}-1\right)}{\ln N_{p o t}}
$$

Onde:

$\mathrm{d}_{2}=$ Índice de diversidade futura de Odum;

$\mathrm{Sad}=$ Número de espécies futuras;

Npot = Somatória do número de árvores potenciais para a via. 
f) Índice de árvore por quilômetro de via existente

Índice que apresenta o número de árvores por quilômetro linear presente nas ruas. Este valor permite observar se o espaçamento entre plantas está adequado, podendo indicar a necessidade de novos plantios ou mesmo a retirada de árvores. É obtido pela seguinte fórmula, (SILVA FILHO; BORTOLETO, 2005):

$$
\text { larv }=\text { Nexist } / \text { Comprimento da rua }
$$

Onde:

larv = Índice de árvore por quilômetro de via existente;

Nexist = Número de árvores existente na rua;

Comprimento da rua $=\mathrm{km}$.

\section{RESULTADOS E DISCUSSÕES}

\section{Índice de Cobertura Vegetal (ICV), Ìndice de Cobertura Arbórea (ICA) e Índice de Árvore por Quilômetro de Via Existente}

A área total de copas das árvores encontradas nas ruas e avenidas do Bairro Centro Norte da Cidade de Dois Vizinhos chegou a 20685,0 $\mathrm{m}^{2}$ e o Índice de Cobertura Vegetal foi igual a $17,3 \mathrm{~m}^{2} / \mathrm{hab}$. O índice encontrado estaria dentro do recomendado pela Sociedade Brasileira de Arborização Urbana (SBAU, 1996). No entanto, esse índice foi revisto e teve um considerável aumento para ser considerado como ideal. Para a SBAU, até no ano de 1996 o índice mínimo para áreas cobertura vegetal deveria ser de $15 \mathrm{~m}^{2} / \mathrm{hab}$., (SBAU, 1996). Entretanto, na carta do encontro paulista de arborização urbana em Americana - SP, ficou decidido como mínimo de cobertura vegetal $100 \mathrm{~m}^{2} / \mathrm{hab}$. de projeção de copa (SBAU, 2010).

Comparativamente, o índice encontrado para a área deste estudo é melhor do que de outros estudos. Rocha e Werlang (2005) encontraram para o Bairro Centro da cidade de Santa Maria um índice de cobertura vegetal de $6,51 \mathrm{~m}^{2} / \mathrm{hab}$. Para a cidade de Juiz de Fora - MG, Costa e Ferreira (2009) observaram um índice abaixo de $2,5 \mathrm{~m}^{2} / \mathrm{hab}$., muito aquém do recomendado pela SBAU (1996). Na cidade de Mossoró (RN) o índice obtido por Arruda et al. (2013), foi de 9,57 $\mathrm{m}^{2} /$ hab., sendo este um índice um pouco melhor, entretanto, ainda fora do aceitável. Para as cidades de Porto Alegre e Belo Horizonte em ambas as cidades no bairro Centro foram encontrados 4,65 e 15,68 $\mathrm{m}^{2} /$ habitante respectivamente (PEREIRA et al., 2010). 
De acordo com os resultados dos estudos apresentados, observa-se que, assim como na cidade do presente estudo, também em outras cidades do Brasil, o ICV não se apresenta favorável à melhoria da qualidade de vida da população urbana.

O índice de cobertura arbórea encontrado para o bairro foi de $28 \%$. Simões et al. (2014), ao estudarem a estrutura da arborização urbana no bairro Vila Isabel na cidade do Rio de Janeiro afirmaram que nos bairros onde predominam as atividades comerciais é recomendável que se obtenha um ICA mínimo de $30 \%$, e nos bairros com função predominantemente residencial, é recomendável um ICV de no mínimo 50\%. Considerando o fato de que o Bairro Centro Norte abrange uma grande área com atividades comerciais e também área residencial o índice encontrado foi baixo, pois boa parte das ruas inventariadas possui atividades comerciais. De acordo com a literatura seria interessante que o bairro apresentasse um ICA acima de $30 \%$.

Segundo Nucci et al. (2003), para o Bairro Centro de Curitiba a cobertura vegetal obtida foi de $12,56 \%$, abaixo do índice encontrado neste estudo. No entanto, a qualidade da vegetação observada no bairro de Dois Vizinhos não se apresenta em boas condições, contendo vários problemas que devem ser melhorados com atividades de manejo.

Os pelos índices de Cobertura Vegetal e de Cobertura Arbórea expressam a qualidade do ambiente de uma cidade (SHAMS et al., 2009). Sendo assim, os resultados obtidos pelo estudo demonstram que a qualidade do Bairro Centro Norte esta muito baixa, sendo necessário um adensamento arbóreo e incremento de espécies para proporcionar maior sombreamento e melhoria da qualidade de vida da área abrangida pelo bairro.

Para o Índice de árvore por quilômetro de via existente o bairro em estudo também apresenta um déficit onde o número atual de árvores é de 1.206 indivíduos, enquanto que o bairro comportaria 1.371 árvores ao longo de 20569,3 km de vias, com espaçamento adequado de 15 metros entre cada uma das plantas.

\section{Índice de diversidade de Odum}

Os índices de riqueza ou variedade são indicadores de diversidade úteis na análise, podendo ser usados nas decisões de manejo e planos diretores de arborização. Realizar o manejo da arborização levando em consideração o táxon se deve a problemas já ocorridos em algumas cidades brasileiras e na maioria das cidades norte-americanas, em que ocorre o ataque de algum tipo de praga que acaba com boa parte das espécies (SILVA FILHO; BORTOLETO, 2005).

O número de árvores existentes em cada uma das vias foi contabilizado, sendo que a via que apresentou maior diversidade de espécies foi a Rua Marechal Hermes (25 espécies), 
com índice de diversidade igual a 5,8, ou seja, em uma única rua encontram-se muitos táxons. Maior diversidade de espécies nas ruas é muito importante, pois quanto maior a diversidade, maiores as probabilidades de serem evitados problemas com pragas e doenças que podem levar a dizimação ou redução de indivíduos nas ruas. A segunda rua com maior índice foi a Castelo Branco, com índice igual a 4, com 19 espécies distribuídas ao longo da via. Ao contrário dessas ruas, outras não apresentaram nenhuma árvore (espécie), apresentando, portanto, índice de diversidade igual à zero.

O número de exemplares e de espécies por via, bem como, os valores calculados para os índices de diversidade atual e futura são apresentados na tabela 1.

Tabela 1. Distribuição do número de espécies e exemplares por rua, índice de diversidade atual e futuro do bairro Centro Norte da Cidade de Dois Vizinhos - PR

Table 1. Distribution of the number of species and specimens by street, current and future diversity index of North Center neighborhood of Dois Vizinhos - PR

\begin{tabular}{|c|c|c|c|c|c|c|c|}
\hline Nome da Rua & $\begin{array}{c}\mathrm{N}^{\circ} \text { de } \\
\text { espécies } \\
\text { atual (s) }\end{array}$ & $\begin{array}{c}\mathrm{N}^{\circ} \mathrm{de} \\
\text { exemplar/via }\end{array}$ & $\begin{array}{l}\text { Índice de } \\
\text { divers. } \\
\text { atual } \\
\text { (d atual) }\end{array}$ & $\begin{array}{l}\text { Espécies a } \\
\text { serem } \\
\text { adicionadas } \\
\text { ou retiradas } \\
\text { (S ad) }\end{array}$ & $\begin{array}{l}\text { Valor } \\
\text { final de } \\
\text { espécies } \\
\text { na via }\end{array}$ & $\begin{array}{c}\mathrm{N}^{\circ} \text { de } \\
\text { exemplares } \\
\text { potencial }\end{array}$ & $\begin{array}{c}\text { Índice de } \\
\text { divers. } \\
\text { Futuro } \\
\text { (dfut) }\end{array}$ \\
\hline Presidente Costa e Silva & 9 & 130 & 1,6 & 10 & 19 & 135 & 3,7 \\
\hline Inês Pinzom & 17 & 113 & 3,4 & 0 & 17 & 141 & 3,3 \\
\hline Wenceslau Braz & 13 & 104 & 2,6 & 5 & 18 & 136 & 3,4 \\
\hline Prudente de Morais & 13 & 96 & 2,6 & 5 & 18 & 140 & 3,3 \\
\hline Castelo Branco & 19 & 86 & 4,0 & -3 & 16 & 132 & 3,1 \\
\hline Castro Alves & 11 & 75 & 2,3 & 6 & 17 & 150 & 3,2 \\
\hline Souza Naves & 10 & 74 & 2,1 & 7 & 17 & 131 & 3,4 \\
\hline João Dalpasquale & 9 & 70 & 1,9 & 9 & 18 & 152 & 3,3 \\
\hline Bento Munhoz da Rocha & 8 & 69 & 1,7 & 10 & 18 & 128 & 3,4 \\
\hline Marechal Floriano Peixoto & 9 & 65 & 1,9 & 8 & 16 & 140 & 3,3 \\
\hline Rua do Comércio & 8 & 65 & 1,7 & 10 & 18 & 147 & 3,3 \\
\hline Pref. Dedi Barrichelo Mantagner & 9 & 63 & 1,9 & 8 & 17 & 161 & 3,2 \\
\hline Marechal Hermes & 25 & 63 & 5,8 & -12 & 13 & 115 & 2,6 \\
\hline Dom Pedro & 12 & 44 & 2,9 & 3 & 15 & 122 & 3,0 \\
\hline Quintino Bocaiuva & 14 & 32 & 3,8 & -1 & 13 & 86 & 2,8 \\
\hline Ipiranga & 5 & 31 & 1,2 & 12 & 17 & 113 & 3,4 \\
\hline Sete de Setembro & 3 & 11 & 0,8 & 14 & 17 & 145 & 3,2 \\
\hline Zacarias de Vasconcelos & 1 & 7 & 0,0 & 14 & 14 & 20 & 4,5 \\
\hline Vereador Enedir Lima & 3 & 5 & 1,2 & 10 & 10 & 37 & 3,3 \\
\hline Heitor F. Hablich & 2 & 3 & 0,9 & 11 & 12 & 47 & 3,3 \\
\hline 28 de Novembro & 0 & 0 & 0,0 & 16 & 16 & 84 & 3,5 \\
\hline Guilherme A. Giordani & 0 & 0 & 0,0 & 13 & 13 & 22 & 3,9 \\
\hline Médias & 8,36 & 54,81 & 2,01 & - & 15,86 & - & 3,3 \\
\hline Totais & - & 1206 & - & - & - & 2484 & - \\
\hline
\end{tabular}

Das 22 vias inventariadas, apenas 7 apresentaram índice de diversidade considerado como bom, acima de 2,45. O índice bom foi verificado para as ruas: Marechal Hermes, Castelo 
Branco, Quintino Bocaíuva, Inês Pinzom, Dom Pedro, Wenceslau Braz e Prudente de Morais. Contudo, as ruas Marechal Hermes, Castelo Branco, Quintino Bocaíuva apresentam muitas espécies no total, fato que dificulta as ações de manejo e desenvolvimento adequado dos indivíduos arbóreos, devido à ausência de espaço provocado pelo grande número de árvore. Assim, é indicada a retirada de algumas espécies nestas ruas, o que consequentemente reduz o índice de diversidade, porém possibilita melhor desempenho das funções ambientais pelas espécies que se encontram nestas vias.

As demais ruas apresentam valores inadequados. O que resultou em um valor médio da diversidade de Odum para o bairro de 2,01, valor abaixo do considerado como mínimo. Portanto, faz-se necessário a implantação de novas espécies em algumas ruas no bairro.

Em nível de comparação, em estudo realizado na cidade de Águas de São Pedro SP, Silva Filho e Bortoleto (2005) encontraram um índice de Odum atual de 19,50; 13,98 e ainda 7,11 para as diferentes áreas avaliadas, índices de diversidade bem elevados, o que demostram grande quantidade de espécies. Ruas com tais índices apresentam maiores complicações em relação ao manejo, pois cada espécie apresenta diferentes comportamentos e necessidades à sobrevivência.

Quanto ao número de espécies que poderão ser adicionadas ou removidas nas vias do Bairro Centro Norte, os resultados dos índices mostraram que ocorre uma variação na quantidade. Para as ruas Castelo Branco, Marechal Hermes e Quintino Bocaiuva, deverá ocorrer a remoção, especialmente de Ligustrum lucidum W.T.Ait. (Alfeneiro). Para as demais ruas, será necessário o adensamento de espécies, que varia de 3 a 16 espécies, sendo a maior quantidade (16) para a rua 28 de Novembro que fica localizada no centro da cidade e não possui nenhuma espécie, conforme mostrado na tabela 1.

Com a adição ou remoção do número de espécies recomendado, o índice de todas as ruas teria uma melhora, assumindo o valor médio para o bairro de 3,3 , superior ao valor de 2,01 inicial (inadequado) e superior a 2,45 que é satisfatório, proporcionando desta forma maior qualidade ambiental, com relação à diversidade de espécies, e assim o número de exemplares arbóreos chegaria a 2.484 árvores distribuídas adequadamente ao longo das ruas do Bairro Cento Norte.

Com base no índice de diversidade de Odum, haverá um aumento considerável no número de indivíduos arbóreos nas vias do bairro, passando de 1.206 árvores existentes na atualidade para 2.484 no futuro. Este aumento deverá gerar benefícios ambientais para o bairro, bem como, a melhoria da qualidade de vida de seus habitantes. 


\section{CONCLUSÃO}

O Bairro Centro Norte apresenta em termos de arborização uma realidade muito parecida com outras cidades brasileiras, com a distribuição irregular de exemplares arbóreos ao longo das vias. Enquanto algumas ruas se encontram bem arborizadas e com boa diversidade de espécies, que resultaram em índices de diversidade acima de 3,8, chegando até a 5,8 e outras vias não apresentam nenhum indivíduo arbóreo. Essa distribuição irregular da arborização ao longo das vias é resultado de uma arborização implantada sem qualquer planejamento e conduzida sem manejo adequado, resultando em Índice de Cobertura Vegetal de 17,3 m²/habitante e Índice de Cobertura Arbórea de 25,8\%, ambos abaixo do recomendado conforme consta na literatura.

Os resultados obtidos apontam para a necessidade do adensamento arbóreo e do enriquecimento de espécies que poderão proporcionar maior sombreamento e melhoria da qualidade de vida urbana do bairro. Contudo, essas intervenções na arborização atual deverão ser de forma planejada e com manejo adequado para que a vegetação seja capaz de cumprir com sua função ambiental na área estudada.

\section{REFERÊNCIAS}

ALVARES, C. A.; STAPE, J. L.; SENTELHAS, P. C.; de MORAES GONÇALVES, L. J.; SPAROVEK, G. Köppen's climate classification map for Brazil. Meteorologische Zeitschrift, Stuttgart, v. 22, n. 6, p. 711-728, 2013.

ANDREATTA, T. R.; BACKES, F. A. A. L.; BELLÉ,R. A.; NEUHAUS, M.; GIRARDI, L. B.; SCHWAB, N. T.; BRANDÃO, B. S. Análise da arborização no contexto urbano de avenidas de Santa Maria, Revista Brasileira de Arborização Urbana, Piracicaba, v.6, n.1, p. 36-50, 2011.

ANGELIS NETO, G.; ANGELIS, B. L. D.; DALL'AGNOL, I.C.S.; KRELING, W. L. O controle de processos em áreas urbanas com o uso da vegetação. Revista da Sociedade Brasileira de Arborização Urbana, Piracicaba, v.1, n.1, p. 56-61, 2006.

ARRUDA, L. E. V.; SILVEIRA, P. R. de S.; VALE, H. S. M.; SILVA, P. C. M. Índice de área verde e de cobertura vegetal no perímetro urbano central do município de Mossoró-RN. Revista Verde, Mossoró, v. 8, n. 2, p.13-17, 2013.

COLETTO, E. P.; MÜLLER, N. G.; WOLSKI, S. S. Diagnóstico da arborização das vias públicas do município de Sete de Setembro (RS). Revista da Sociedade Brasileira de Arborização Urbana, Piracicaba, v. 3, n. 2, p. 110-122, 2008.

COSTA, R. G.; FERREIRA, C. C. M. Análise do índice de áreas verdes (IAV) na área central da cidade de Juiz de Fora, MG. Revista da Sociedade Brasileira de Arborização Urbana, Piracicaba, v. 4, n. 1, p. 39-57, 2009. 
GOOGLE MAPS. Dois Vizinhos. 1 p. Disponível em: <https://maps.google.com.br/>. Acesso em: 24 jan. 2014.

HARDER, I. C. F.; RIBEIRO, R. C. S.; TAVARES, A. R. Índice de área verde e cobertura vegetal para as praças do município de Vinhedo - SP. Revista Árvore, Viçosa, v. 30, n. 2, p. 277-282, 2006.

INSTITUTO BRASILEIRO DE GEOGRAFIA E ESTATISTICA (IBGE). Censo. 2010, 1 p. Disponível em: <http://censo2010.ibge.gov.br/noticiascenso ?view=noticia\&id=3\&idnoticia $=1766 \&$ busca $=1 \& \mathrm{t}=$ censo-2010-populacao-brasil-190-732694-pessoas>. Acesso em: 07 jan. 2014.

MASCARÓ, L.; MASCARÓ, J. Vegetação urbana. 2.ed. Porto Alegre: Mais Quatro Editora, Porto Alegre, 2005. 204 p.

MELAZO, G. C.; NISHIYAMA, L. Mapeamento da cobertura arbóreo-arbustiva em quatro bairros da Cidade de Uberlândia- MG. Revista Brasileira de Arborização Urbana, Piracicaba, v. 5 , n. 2, p. 52-66, 2010.

NOWAK, D. J.; WALTON, J. T.; STEVENS, J. C.; CRANE, D. E.; HOEHN, R. E. Effect of plot and sample size on timing and precision of Urban Forest Assessments. Arboriculture \& Urban Forestry, Champaign, IL, v. 34, n. 06, p.386-390, 2008.

NUCCI, J. C.; WESTPHALEN, L. A.; FILHO, A. T. B.; NEVES, D. L.; OLIVEIRA, F. A. H. D.; KROKER, R. Cobertura Vegetal no bairro Centro de Curitiba/PR. In: SIMPÓSIO BRASILEIRO DE GEOGRAFIA FÍSICA APLICADA, Rio de Janeiro, 2003. Anais... Rio de janeiro: GEOUERJ, 2003, p. 14.

ODUM, E. P. Fundamentos de ecologia. Fundação Calouste Gulbenkian, Lisboa, 2001. 927 p.

PEREIRA, M. C.; ROCHA, J. R.; MENGUE, V. P. Comparação de índices e espacialização da cobertura vegetal arbórea dos bairros centro de duas metrópoles brasileiras: Belo Horizonte e Porto Alegre. Revista Brasileira de Arborização Urbana, Piracicaba, v. 5, n. 1, p-106-125, 2010.

ROCHA, J. R.; WERLANG, M. K. Índice de cobertura vegetal em Santa Maria: o caso do Bairro Centro. Ciência e Natura, Santa Maria, v. 27, n. 2, p. 85-99, 2005.

ROPPA, C.; FALKENBERG, J. R.; STANGERLIN, D. M.; BRUN, F. G. K.; BRUN, E. J.; LONGHI, S. J. Diagnóstico da percepção dos moradores sobre a arborização urbana na Vila Estação Colônia - Bairro Camobi, Santa Maria - RS. Revista da Sociedade Brasileira de Arborização Urbana, Piracicaba, v. 2, n. 2, p. 11-30, 2007.

SANTOS, A. F.; JOSÉ, A. C.; SOUSA, P. A. de. Fitossociologia e diversidade de espécies arbóreas das praças centrais do município de Gurupi -TO. Revista Brasileira de Arborização Urbana, Piracicaba, v. 8, n. 4, p. 36-46, 2013.

SHAMS, J. C. A; GIACOMELI, D. C.; SUCOMINE; N. M. Emprego da arborização na melhoria do conforto térmico nos espaços livres públicos. Revista da Sociedade Brasileira de Arborização Urbana, Piracicaba, v. 4, n. 4, p.1-16, 2009. 
SILVA FILHO, D. F.; BORTOLETO, S. Uso de indicadores de diversidade na definição de plano de manejo da arborização viária de Águas de São Pedro-SP. Revista Árvore. Viçosa, v. 29, n. 6, p. 973-982, 2005.

SIMÕES, L. O. C.; MAROTTA, H. R.; PIRES, B. B. M.; COSTA, A. J. S. T. Arborização urbana no Rio de Janeiro (RJ): proposta de manejo e intervenção urbanística do poder público. In: $X$ SIMPÓSIO BRASILEIRO DE GEOGRAFIA FÍSICA APLICADA, Rio de Janeiro 2014. Anais... Rio de Janeiro, 2014, p. 8. Disponível em: < http://www.cibergeo.org/XSBGFA/eixo3/3.4/243/243.htm> . Acesso em: 29 jul. 2014.

SOCIEDADE BRASILEIRA DE ARBORIZAÇÃO URBANA (SBAU). "Carta a Londrina e Ibiporã". Boletim Informativo, Londrina, v. 3, n. 5, 1996, p.3.

SOCIEDADE BRASILEIRA DE ARBORIZAÇÃO URBANA (SBAU). Carta De Americana - São Paulo. In: $3^{\circ}$ Encontro Paulista de Arborização Urbana, 2010. Disponível em: < http://www.sbau.org.br/img-sbau/Carta_Americana_2010.pdf>Acesso em: 03 agos. 2014.

TOLEDO, F. S; SANTOS, D. G. Espaços Livres de Construção. Revista da Sociedade Brasileira de Arborização Urbana, Piracicaba, v. 3, n.1, p. 73-91, 2008. 